\title{
EFFECT OF COLD SWAGING ON THE MECHANICAL AND MICROSTRUCTURE CHARACTERISTICS OF TUNGSTEN HEAVY ALLOY
}

\author{
R.Osama ${ }^{1}$, A.S.abdalla ${ }^{2}$, W.M.Elthalabawy ${ }^{3}$, G.M.Abdo ${ }^{4}$, M.T.Sallam ${ }^{5}$ \\ ${ }^{1}$ Eng, Technical Research Center, Cairo, Egypt \\ ${ }^{2}$ Dr.Eng, Technical Research Center, Cairo, Egypt \\ ${ }^{3}$ Dr.Eng, Material Science and Technology department, Military Technical College, Cairo, Egypt \\ ${ }^{4}$ Dr.Eng, Technical Research Center, Cairo, Egypt \\ ${ }^{5}$ Professor, Head of Material Science and Technology department, Military Technical College, Cairo, Egypt
}

\begin{abstract}
In this experimental investigation, the post sintering mechanical treatment was implemented by cold swaging the produced tungsten alloy rods with composition (90W-7Ni-3Fe \%wt) by cold isostatic press with $300 \mathrm{MPa}$, and appling different reductions of cross sectional area varying from $10 \%$ up to $50 \%$. On the mechanical and microstructure properties of the tungsten heavy all oy (89.97W-7Ni-3Fe-0.03 Y2O3 \%wt). Elemental powders were mixed for 120 min. Green compacted by cold isostatic press with $300 \mathrm{MPa}$, and Finally the specimens were sintered at $1480^{\circ} \mathrm{C}$ for 90 min under vacuum atmosphere. It was found that the ultimate tensile strength and hardness were remarkably increased by about $39 \%$ and $45 \%$ respectively, by the application of $50 \%$ area reduction by swaging, relative to the sintered specimens. On the other hand, ductility and impact resistance were deeply decreased by about $75 \%$ and $53 \%$ respectively, by also, the application of $50 \%$ area reduction by swaging.
\end{abstract}

Keywords: Cold Swaging, Liquid Phase Sintering, Tungsten Heavy Alloy, Powder Metallurgy.

\section{INTRODUCTION}

Tungsten heavy alloys, containing from 88 to $97 \%$ wt tungsten as a base ingredient having $\mathrm{BCC}$ structure and a binding matrix of Ni-Fe having FCC structure are widely uses in many application like kinetic energy penetrator, air to air rocket nozzles and armor plating. That is due to their very strong inter-atomic bonding, high mechanical properties, low heat conductivity, low thermal expansion, and high corrosion resistance[1,2].

In order to achieve as high kinetic energy as possible for kinetic energy penetrators, high density materials are required. Only there are two important candidate materials which can satisfy this high density requirement, they are depleted uranium (DU), and tungsten heavy alloys. DU alloys are currently the most widely used and favored materials for log rod kinetic energy penetrators.

This is essentially attributed to the high density, and elevated mechanical properties, in addition to the selfsharpening phenomenon that results from the adiabatic shear that generally occurs during material deformation at high strain rates[3].

Because of the increasing environmental concerns due to contamination, resulting from residual radiation, intensive efforts were done to find suitable substitutes for these alloys. In the last decades, extensive researches were carried out to improve the penetration and ballistic properties of tungsten heavy alloys to be the appropriate substitute of DU alloys.

To enhance the mechanical and the ballistic characteristics of tungsten heavy alloys, there are several approaches, the first, by modifying the composition either by optimizing the proportions of tungsten and the other matrix ingredients $(\mathrm{Ni}$, $\mathrm{Fe}$, ...etc.) or by Adding different types of oxides, like yttrium oxides [4-6], aluminum oxides [7] and zirconium oxides[4]. The second, by optimizing the processing parameters (compaction pressure, sintering temperature, time, and atmosphere). The third approach, by post thermal and mechanical treatments. In this work, the effect of applying a cold swaging (mechanical treatment) on the mechanical and structure properties will be the main concern.

\section{EXPERIMENTAL WORK}

A heavy tungsten alloy having the composition $89.97 \%$ wt $\mathrm{W}, 7 \%$ wt $\mathrm{Ni}, 3 \%$ wt $\mathrm{Fe}$, and $0.03 \%$ wt $\mathrm{Y} 2 \mathrm{O} 3$ and was chosen, as a base alloy, to evaluate the effect of post sintering mechanical treatment, on the mechanical and structure properties of this alloy. The characteristics of the elemental powders are given in Table 1, and the morphologies of the different powders are illustrated in Fig-1.

The alloy with the prescribed basic composition were mixed in a planetary mixer for $120 \mathrm{~min}$.The mixtures were consolidated into green compacts using the cold isostatic 
pressing technique under $300 \mathrm{MPa}$. The compacted specimens were then liquid phase sintered, in vacuum, at a temperature of $1480^{\circ} \mathrm{C}$ for $90 \mathrm{~min}$. Specimens in the form sintered round tungsten heavy alloy rods were subjected to mechanical treatment by swaging using TORRINGTON ROTARY SWAGING machine type $1047-4 \mathrm{vs}$. The cross sectional areas of specimens were reduced using a rotating hummers and the percentage of reduction was controlled by allowing the tungsten rod to flow through a special dies with variable inlet diameters of $6.85,7.4,7.78,8.4,8.5$, and $9.3 \mathrm{~mm}$ and a fixed outlet diameter of $6.56 \mathrm{~mm}$, to achieve the require swaging percentages which are 10,20,30,40, and $50 \%$ respectively.

Table -1: Characteristics of the ele mental and the oxide powders

\begin{tabular}{|l|l|l|l|l|}
\hline Powder & $\mathrm{W}$ & $\mathrm{Ni}$ & $\mathrm{Fe}$ & $\mathrm{Y}_{2} \mathrm{O}_{3}$ \\
\hline Shape & polygonal & sponge & $\begin{array}{l}\text { Nearly } \\
\text { spherical }\end{array}$ & flake \\
\hline Partic le size $(\mu \mathrm{m})$ & $1-3$ & $.5-3$ & $1-5$ & $3-4$ \\
\hline App density $(\mathrm{g} / \mathrm{cm} 3)$ & 4.3 & 3.1 & 2.6 & 1.6 \\
\hline $\begin{array}{l}\text { Melting } \\
\text { temperature }\left({ }^{\circ} \mathrm{C}\right)\end{array}$ & 3410 & 1453 & 1538 & 2425 \\
\hline Density $(\mathrm{g} / \mathrm{cm} 3)$ & 19.3 & 8.9 & 7.87 & 5.01 \\
\hline
\end{tabular}

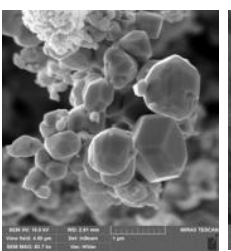

(a)

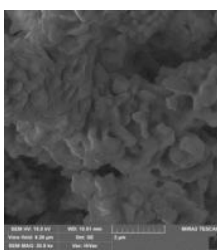

(b)

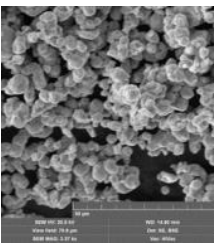

(c)

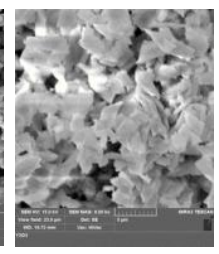

(d)
Fig -1: The morphology of the different used powders. (a) Tungsten, (b) Nickel, (c) Iron, (d) Yttrium Oxide powder.

Density of the obtained sintered specimens was measured by Archimedes water immersion technique. Tensile test was carried out using Instorn tensile test machine type 8032 with loading rate control $8 \mathrm{kN} \backslash$ min. Impact test was carried out using Galdbini charpy pendulum impact testing machine. Hardness values where measured by Rockwell hardness testing machine. The fractures and microstructures of the different specimens were obtained using scanning electron microscope (SEM) type Seo 202.

\section{RESULTS AND DISCUSSIONS}

\subsection{Effect on the physical and mechanical \\ properties}

The measurement of density of the five different specimens of the same alloy produced under different area reduction percentages $(10,20,30,40$, and $50 \%)$ using rotary swaging showed that, a slight increase of relative density can be reported between 10 and $20 \%$ of area reductions, while with higher reductions of area did not reveal any significant change of relative density, as shown in Fig-2. B. Katavić [8], reported that, rotary swaging has very limited effect on alloy density particularly in tungsten heavy alloys.

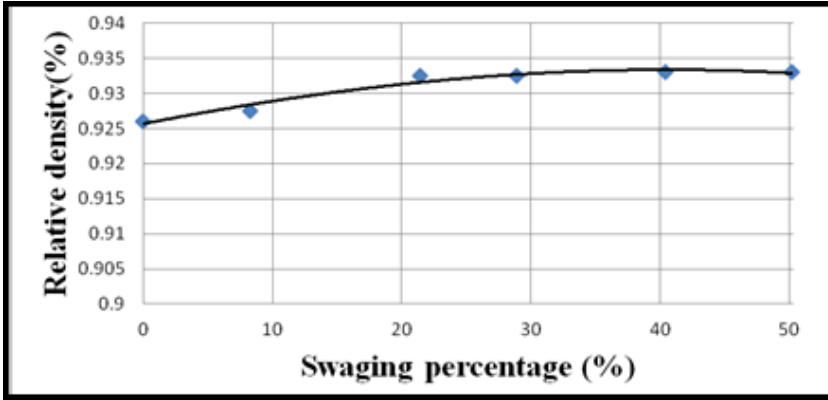

Fig -2: Effect of rotary swaging on the relative density of tungsten heavy alloy $(89.97 \mathrm{~W}-7 \mathrm{Ni}-3 \mathrm{Fe}-0.03 \mathrm{Y} 2 \mathrm{O} 3 \% \mathrm{wt})$ obtained under different reductions of cross sectional area and a sintering temperature of $1480^{\circ} \mathrm{C}$.

Fig- 3, illustrates the evolution of the mechanical properties of the adopted heavy tungsten alloy $(89.97 \mathrm{~W}-7 \mathrm{Ni}-3 \mathrm{Fe}-$ $0.03 \mathrm{Y} 2 \mathrm{O} 3 \% \mathrm{wt}$ ) with the application of different reductions of cross sectional area using rotary swaging technique. It is evident that, the ultimate tensile strength, and hardness are monotonically increased, while the ductility and the impact energy steadily decreased with increasing swaging percentages. The ultimate tensile strength and hardness were remarkably increased by about $39 \%$ and $45 \%$ respectively, by the application of $50 \%$ area reduction by swaging, relative to the sintered specimens. On the other hand, ductility and impact resistance were deeply decreased by about $75 \%$ and $53 \%$ respectively, by also, the application of $50 \%$ area reduction by swaging. It was shown by $M$. Nikačević et al $[8,9]$ that, During rotary swaging, strength intensively increases, while ductility and toughness were found to be quite reduced compared to the initial sintered condition. A high gradient of hardness in the rods cross section can be noticed as well.

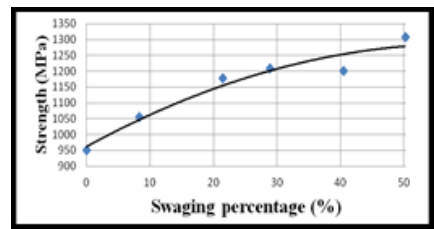

(a)

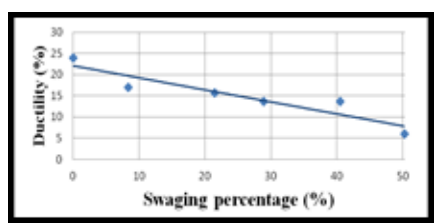

(c)

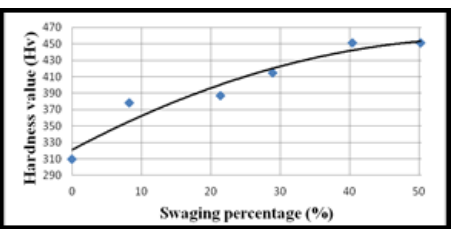

(b)

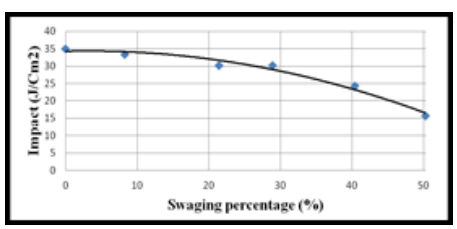

(d)
Fig -3 : Effect of rotary swaging on the mechanical properties of tungsten heavy alloy $(89.97 \mathrm{~W}-7 \mathrm{Ni}-3 \mathrm{Fe}-$ $0.03 \mathrm{Y} 2 \mathrm{O} 3 \% \mathrm{wt}$ ) obtained under different cross section area reduction and at sintering temperature of $1480^{\circ} \mathrm{C}$ : a) Tensile strength b) hardness c) ductility d) impact

\subsection{Effect on Microstructure}

Fig-4. Demonstrates the obtained Transverse cross-section microstructures of the adopted heavy tungsten alloy specimens obtained under different values of area reductions by rotary swaging. The examined microstructures showed 
that; there is a significant reduction of distances among the centers of $\mathrm{W}$ grains. Moreover, a clearly visible grain deformation can be recognized particularly at the structures subjected to heavy percentages of deformation under the swaging process. B. Katavić $[8,9]$ reported that, there are no significant changes in the $\mathrm{W}$ phase grain size or in the volume fraction of $\mathrm{W}$ and matrix phases as an effect of plastic deformation after rotary swaging while the mean distance between $\mathrm{W}$-grains was found to be reduced.

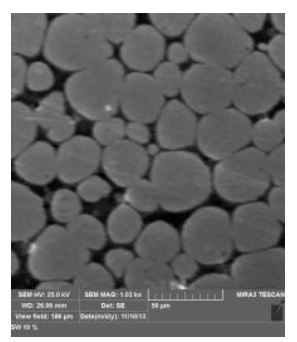

(a)

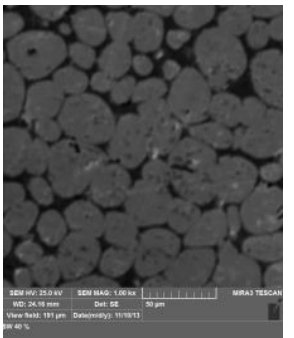

(d)

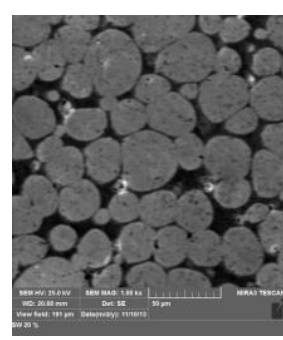

(b)

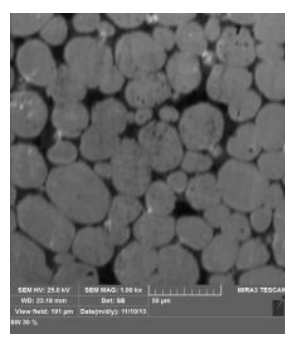

(c)

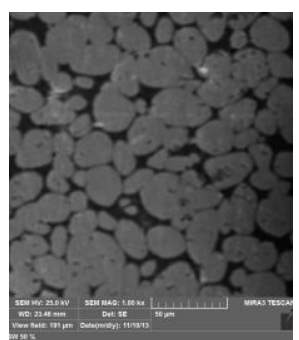

(e)
Fig -4: Effect of rotary swaging on the Trans verse cross section mic rostructure of tungsten heavy alloy $(89.97 \mathrm{~W}$ -

$7 \mathrm{Ni}-3 \mathrm{Fe}-0.03 \mathrm{Y} 2 \mathrm{O} 3 \% \mathrm{wt}$ ) obtained under different

reductions of cross sectional area and a sintering temperature of $1470^{\circ} \mathrm{C}$ : a) $10 \%$ b) $20 \%$ c) $30 \%$ d) $40 \%$ e) $50 \%$.

While the longitudinal cross-section Microstructure of the adopted heavy tungsten alloy specimens obtained under different values of area reductions by rotary swaging was shown in Fig.5. It was noted that, as the swaging percentage increase the grain elongation on the deformation axis increase. Also U. Ravi Kiran [10] reported that, The increase in swaging percentage leads to increase in the aspect ratio (L/D) of the tungsten grains in the longitudinal cross section, from about $1: 1$ ( $0 \%$ deformation) to approximately 7:1 (75\% deformation).

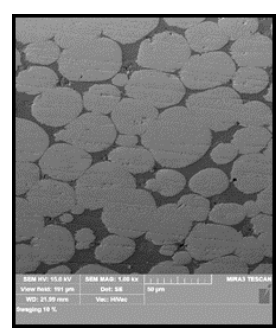

(a)

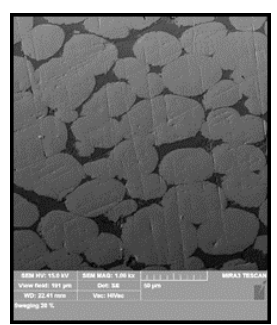

(b)

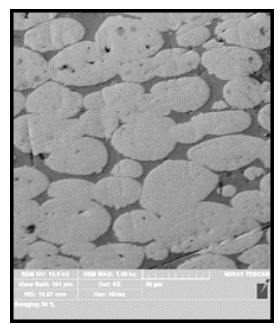

(c)

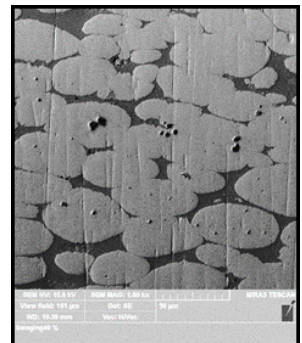

(d)

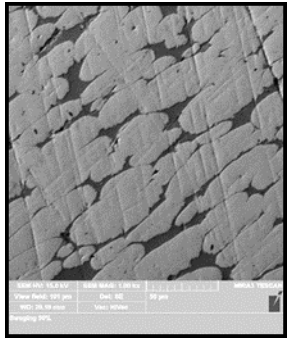

(e)
Fig -5 : Effect of rotary swaging on the longitudinal cross section mic rostructure of tungsten heavy alloy $(89.97 \mathrm{~W}-$

$7 \mathrm{Ni}-3 \mathrm{Fe}-0.03 \mathrm{Y} 2 \mathrm{O} 3 \% \mathrm{wt}$ ) obtained under different reductions of cross sectional area and a sintering temperature of $1470^{\circ} \mathrm{C}$ : a) $10 \%$ b) $20 \%$ c) $30 \%$ d) $40 \%$ e) $50 \%$.

\subsection{Effect on the Fracture Surface}

The tensile fracture surfaces obtained, using SEM of the WHA specimens produced by applying different area reduction percentages using rotary swaging, are shown in Fig.6. The fracture surfaces of the specimens subjected to low reductions of area by swaging revealed mixed mode fractures by intergranular, W-W particles, and cleavage separations. Also, we can easily note that as swaging percentages increase the amount of cleavage fracture sensibly increases, which clearly indicate the occurrence of significant strengthening effect by Appling this mechanical treatment.

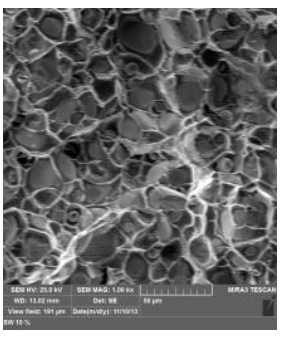

(a)

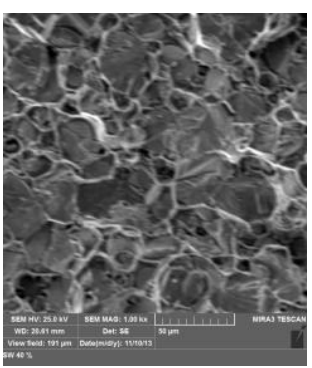

(d)

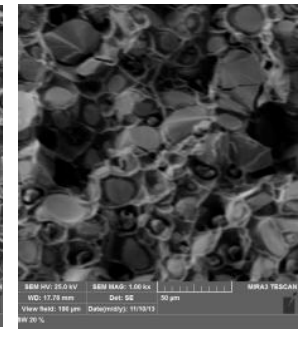

(b)

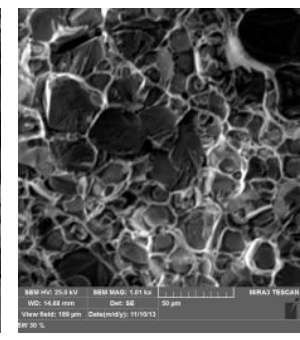

(c)

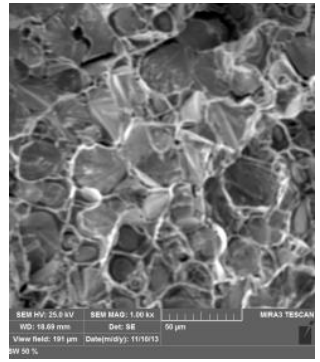

(e)
Fig - 6: Effect of rotary swaging on the fracture surface of tungsten heavy alloy (89.97W-7Ni-3Fe-0.03 Y2O3\%wt) obtained under different reductions of cross sectional area and a sintering temperature of $1470^{\circ} \mathrm{C}$ : a) $10 \%$ b) $20 \%$ c) $30 \%$ d) $40 \%$ e) $50 \%$. 


\section{CONCLUSIONS}

- The application of mechanical treatment of the tungsten heavy alloy, studded by applying a rotary swaging machine, showed that as the percentage cross sectional area decreases the tensile and hardness value increases, while ductility and impact energy decreases.

- The optimum rotary swaged mechanical properties achieved at a reduction of $30 \%$ of the cross-sectional area.

\section{REFERENCES}

[1] C.M.S. Fernandes, (2008).

[2] A. Bose, R. German, Metallurgical and Materials Transactions A 21 (1990) 1325-1327.

[3] S. Andrew, R. Caligiuri, L. Eiselstein, Tungsten and tungsten alloys: Recent advances, Plenum Press, NY (1991).

[4] K.H. Lee, S.I. Cha, H.J. Ryu, S.H. Hong, Materials Science and Engineering: A 452 (2007) 55-60.

[5] F. Jing-lian, L. Tao, C. Hu i-chao, W. Deng-long, Journal of Materials Processing Technology 208 (2008) 463-469.

[6] K.H. Lee, S.I. Cha, H.J. Ryu, S.H. Hong, Materials Science and Engineering: A 458 (2007) 323-329.

[7] Ö.U. Demirkan, A. Genç, M.L. Öveçoğlu, International Journal of Refractory Metals andHard Materials 32 (2012) 33.

[8] B. Katavić, M. Nikačević, Z. Odanović, Science of Sintering 40 (2008) 319-331.

[9] B. Katavić, Z. Odanović, M. Burzić, Materials Science and Engineering: A 492 (2008) 337-345.

[10] U. Ravi Kiran, A. Sambasiva Rao, M. Sankaranarayana, T. Nandy, International Journal of Refractory Metals and Hard Materials (2012). 